\title{
The PB2, PA, HA, NP, and NS genes of a highly pathogenic avian influenza virus $A$ /whooper swan/Mongolia/3/2005 (H5N1) are responsible for pathogenicity in ducks
}

Masahiro Kajihara ${ }^{1,3}$, Yoshihiro Sakoda ${ }^{1}$, Kosuke Soda ${ }^{1,4}$, Kenji Minari $^{1}$, Masatoshi Okamatsu' ${ }^{1}$, Ayato Takada ${ }^{2}$ and Hiroshi Kida ${ }^{1,2^{*}}$

\begin{abstract}
Background: Wild ducks are the natural hosts of influenza A viruses. Duck influenza, therefore, has been believed inapparent infection with influenza A viruses, including highly pathogenic avian influenza viruses (HPAIVs) in chickens. In fact, ducks experimentally infected with an HPAlV strain, A/Hong Kong/483/1997 (H5N1) (HK483), did not show any clinical signs. Another HPAIV strain, A/whooper swan/Mongolia/3/2005 (H5N1) (MON3) isolated from a dead swan, however, caused neurological dysfunction and death in ducks.
\end{abstract}

Method: To understand the mechanism whereby MON3 shows high pathogenicity in ducks, HK483, MON3, and twenty-four reassortants generated between these two H5N1 viruses were compared for their pathogenicity in domestic ducks.

Results: None of the ducks infected with MON3-based single-gene reassortants bearing the PB2, NP, or NS gene segment of HK483 died, and HK483-based single-gene reassortants bearing PB2, NP, or NS genes of MON3 were not pathogenic in ducks, suggesting that multiple gene segments contribute to the pathogenicity of MON3 in ducks. All the ducks infected with the reassortant bearing PB2, PA, HA, NP, and NS gene segments of MON3 died within five days post-inoculation, as did those infected with MON3. Each of the viruses was assessed for replication in ducks three days post-inoculation. MON3 and multi-gene reassortants pathogenic in ducks were recovered from all of the tissues examined and replicated with high titers in the brains and lungs.

Conclusion: The present results indicate that multigenic factors are responsible for efficient replication of MON3 in ducks. In particular, virus growth in the brain might correlate with neurological dysfunction and the disease severity.

Keywords: H5N1 influenza virus, Duck, Natural host, Pathogenicity

\section{Background}

Influenza A viruses have eight-segmented, negative, and single-stranded RNA genomes and are serologically divided into 16 hemagglutinin (HA) (H1-H16) and 9 neuraminidase (NA) (N1-N9) subtypes [1,2]. Influenza A viruses are widely distributed in birds and mammals, including humans. Ecological studies have revealed that

\footnotetext{
*Correspondence: kida@vetmed.hokudai.ac.jp

'Department of Disease Control, Graduate School of Veterinary Medicine,

Hokkaido University, Sapporo, Hokkaido 060-0818, Japan

${ }^{2}$ Research Center for Zoonosis Control, Hokkaido University, Sapporo,

Hokkaido 001-0020, Japan

Full list of author information is available at the end of the article
}

wild waterbirds, especially migratory ducks, are the natural hosts of influenza A viruses. Each of the known subtypes of influenza A virus has been perpetuated among water birds and in the water of the lakes where they nest in summer [3,4]. Furthermore, influenza A viruses circulating in nature are nonpathogenic in ducks and evolutionarily static $[5,6]$, suggesting that the viruses and hosts have reached a long-established adaptive optimum. Influenza A viruses maintained in ducks usually do not transmit to and infect chickens directly. It is known that low pathogenic viruses occasionally infect chickens after passage in domestic water birds such as ducks and

\section{Biomed Central}


geese and terrestrial birds such as quails and turkeys, and then may acquire high pathogenicity in chickens through multiple transmissions in the chicken population [7]. Highly pathogenic avian influenza viruses (HPAIVs) are so far restricted to $\mathrm{H} 5$ and $\mathrm{H} 7$ viruses, although most of the viruses of these subtypes are not highly pathogenic in chickens [8]. In 1997, outbreaks of highly pathogenic avian influenza (HPAI) occurred at live bird markets in Hong Kong and human cases of infection with the H5N1 virus were found $[9,10]$. Since then, H5N1 HPAIVs have thus been circulating in poultry for more than a decade [11].

It was generally thought that ducks could tolerate infection with influenza A viruses, including HPAIVs. In fact, A/Hong Kong/483/1997 (H5N1) (HK483) was not lethal for experimentally infected ducks [12]; however, in 2002, a large number of water birds, including ducks, geese, and other birds, died due to infection with H5N1 HPAIVs in Hong Kong [13]. In 2005, approximately six thousand migratory water birds were found dead with H5N1 virus infection in Qinghai Lake, China [14,15] and then virus strains of this subtype have been isolated in the Middle East, Europe, and Africa [16]. Since 2005, H5N1 HPAIVs originating from southern China have been isolated from dead aquatic birds such as swans and geese on their migratory routes to the northern nesting lakes in spring in Japan, Mongolia, and Russia [17-19]. It was reported that ducks experimentally infected with A/whooper swan/Mongolia/3/2005 (H5N1) (MON3) showed neurological dysfunction and died [17]. The mechanism whereby these H5N1 HPAIVs show high pathogenicity in ducks is still unclear.

In chickens, it is well known that insertion of a pair of dibasic amino acid residues at the cleavage site of the HA renders avian influenza viruses capable of infecting endothelial cells, followed by systemic infection [20-22]. Both HK483 and MON3 have multiple basic amino acid residues at the HA cleavage site, representing their high pathogenicity in chickens. The difference in pathogenicity in ducks between HK483 and MON3 hence suggests that factors other than the cleavage activation of the HA molecule contribute to the pathogenicity in ducks. To understand the molecular basis of the high pathogenicity of MON3 in ducks, reassortants were generated between HK483 and MON3 by reverse genetics and compared for their pathogenicity in domestic ducks. The present results indicate that multigenic factors were involved in the high pathogenicity of MON3 in ducks.

\section{Results}

Pathogenicity of H5N1 viruses in ducks of different ages

To investigate whether the age of ducks affects their susceptibility to H5N1 virus infection, either HK483 or MON3 was inoculated intranasally into 1-day-, 2-week-, and 4-week-old domestic ducks and clinical symptoms were monitored up to 14 days post-inoculation (dpi). None of the ducks inoculated with HK483 showed clinical signs for 14 days. On the other hand, all of the 1-day- and 2-week-old ducks inoculated with MON3 died by 3 and $7 \mathrm{dpi}$, respectively (Table 1). They showed depression and convulsion and some of the 2-week-old ducks showed torticollis. In 4-week-old ducks, two of the three birds infected with MON3 survived, although they showed depression, torticollis, and blindness. On 3 dpi, 1-day-, 2-week-, and 4-week-old ducks infected with either HK483 or MON3 were euthanized and lung and brain samples were collected to assess virus replication in ducks at different ages (Table 1). HK483 was recovered from each of the tissues tested from 1-day-old ducks; however, replication of HK483 was restricted in 2- and 4-week-old ducks; HK483 was not detected either in the brains of 2-week-old ducks or in the brains, tracheas, and livers of 4-week-old ducks (data not shown). On the other hand, MON3 was recovered from each of the tissues of ducks experimentally infected regardless of their age. As shown with high titers in the brains and lungs, both viruses replicated more efficiently in 1-dayand 2-week-old ducks than 4-week-old ducks (Table 1). The present data demonstrate that younger ducks were more susceptible to HK483 and MON3 than older ducks. In the following experiments, 2-week-old ducks were adopted, since obvious difference was found in mortality and virus replication in their brains between HK483 and MON3 infection.

\section{Gene segments responsible for pathogenicity of MON3 in ducks}

In order to identify the gene segments responsible for the high pathogenicity of MON3 in ducks, MON3-based reassortants bearing a single segment of HK483 and the other seven segments of MON3 (HK483 PB2/MON3,

\begin{tabular}{|c|c|c|c|c|c|}
\hline \multirow[t]{2}{*}{ Virus } & \multirow{2}{*}{$\begin{array}{l}\text { Age of } \\
\text { ducks }\end{array}$} & \multirow[t]{2}{*}{ Mortality $^{a}$} & \multirow{2}{*}{$\begin{array}{l}M^{\prime} D^{b} \\
\text { (range) }\end{array}$} & \multicolumn{2}{|l|}{ Virus titers ${ }^{c}$} \\
\hline & & & & Brain & Lung \\
\hline \multirow[t]{3}{*}{ HK483 } & 1 day & $0 / 3$ & $\geq 14$ & $5.4,2.5,2.5$ & $5.5,4.5,2.5$ \\
\hline & 2 weeks & $0 / 6$ & $\geq 14$ &,,$---{ }_{-}^{d}$ & $4.3,3.5,2.5$ \\
\hline & 4 weeks & $0 / 3$ & $\geq 14$ &,,--- & $2.5,-,-$ \\
\hline \multirow[t]{3}{*}{ MON3 } & 1 day & $9 / 9$ & $2.2(2-3)$ & $8.0,7.5$ & $5.7,5.5$ \\
\hline & 2 weeks & $10 / 10$ & $4.9(4-7)$ & $8.8,7.3,7.3$ & $8.5,5.5,5.3$ \\
\hline & 4 weeks & $1 / 3$ & 7.0 & $5.5,4.5,-$ & $4.5,2.5,3.7$ \\
\hline
\end{tabular}

${ }^{a}$ Number of dead ducks/number of examined ducks.

${ }^{b}$ Mean death days post-inoculation.

c At 3 days post-inoculation, the brains and lungs were collected. Suspension of each tissue sample was inoculated into 10-day-old embryonated eggs for titration. Virus titers in tissues were expressed as log 50\% egg infectious dose $\left(E_{50}\right) / g$. The lower limit of detection was $10^{1.5} \mathrm{EID}_{50} / \mathrm{g}$.

$\mathrm{d}_{-:}<1.5 \log \mathrm{EID}_{50} / \mathrm{g}$. 
HK483 PB1/MON3, HK483 PA/MON3, HK483 HA/ MON3, HK483 NP/MON3, HK483 NA/MON3, HK483 $\mathrm{M} / \mathrm{MON} 3$, and HK483 NS/MON3) were inoculated intranasally into three 2-week-old ducks to assess their pathogenicity. All ducks infected with HK483 NA/ MON3 or HK483 M/MON3 showed severe depression and died on 5 to $7 \mathrm{dpi}$, as did ducks infected with MON3 (Figure 1). Pathogenicity of HK483 PB1/MON3, HK483 PA/MON3, and HK483 HA/MON3 in ducks was slightly lower than MON3 (i.e., one of three ducks infected with each reassortant survived for 14 days), although all ducks showed depression and the surviving duck infected with HK483 PB1/MON3 developed severe torticollis. HK483 PB2/MON3, HK483 NP/MON3, and HK483 NS/MON3 did not exhibit lethality in ducks, whereas some of the ducks infected with these reassortants showed lethargy and/or mild torticollis (Figure 1). Similarly, HK483-based reassortants bearing a single segment of MON3 and the other seven segments of HK483 (MON3 PB2/HK483, MON3 PB1/HK483, MON3 PA/HK483, MON3 HA/ HK483, MON3 NP/HK483, MON3 NA/HK483, MON3 $\mathrm{M} / \mathrm{HK} 483$, and MON3 NS/HK483) were inoculated into three 2-week-old ducks. Although some ducks showed mild lethargy, all the ducks survived for the 14-day observation period (Figure 1). These results revealed that the PB2, NP, and NS gene segments of MON3 were prerequisite for high pathogenicity in ducks; however, MON3 PB2/HK483, MON3 NP/HK483, and MON3 NS/HK483 did not cause severe clinical symptoms in any ducks, suggesting that multiple gene factors are involved in the high pathogenicity of MON3 in ducks.

To clarify the minimum set of MON3 gene segments required for its high pathogenicity in ducks, eight multigene reassortants between HK483 and MON3 were compared for their pathogenicity in ducks (Figure 2). These multi-gene reassortants uniformly possessed the MON3 PB2, NP, and NS gene segments prerequisite for high pathogenicity in ducks and the HK483 M and NA gene segments which unlikely contribute to the pathogenicity in ducks. These multi-gene reassortants had 8 possible combinations of the PB1, PA, and HA gene segments from HK483 and MON3 (Figure 2). These reassortants were designated MON3 PB2-NP-NS/HK483, MON3 PB2-PB1-NP-NS/HK483, MON3 PB2-PA-NPNS/HK483, MON3 PB2-HA-NP-NS/HK483, MON3 PB2-PB1-PA-NP-NS/HK483, MON3 PB2-PB1-HA-NPNS/HK483, MON3 PB2-PA-HA-NP-NS/HK483, and MON3 PB2-PB1-PA-HA-NP-NS/HK483. None of the ducks infected with MON3 PB2-NP-NS/HK483, MON3 PB2-PB1-NP-NS/HK483, or MON3 PB2-PA-NP-NS/HK483 manifested any clinical symptoms (Figure 2), except for a duck which showed lethargy upon MON3 PB2-NP-NS/ HK483 infection. All the ducks inoculated with MON3 PB2-HA-NP-NS/HK483 showed depression and one of the three ducks died on 6 dpi. Following depression and cyanosis, all the ducks infected with MON3 PB2-PA-HA-

\begin{tabular}{|c|c|c|c|c|c|c|c|c|c|c|}
\hline \multirow{2}{*}{ Virus } & \multicolumn{8}{|c|}{ Origin of gene segment } & \multirow{2}{*}{ Mortality* } & \multirow{2}{*}{$\mathrm{MDD}^{\star *}$} \\
\hline & PB2 & PB1 & PA & $\mathrm{HA}$ & NP & NA & $\mathrm{M}$ & $\mathrm{NS}$ & & \\
\hline 483 & $\square$ & $\square$ & $\square$ & $\square$ & $\square$ & $\square$ & $\square$ & $\square$ & 0/6 & $14 \leq$ \\
\hline ON3 & $\square$ & $\square$ & $\square$ & $\square$ & $\square$ & $\square$ & $\square$ & $\square$ & $7 / 7$ & $4.9(4-7)$ \\
\hline HK483 PB2/MON3 & $\square$ & $\square \square$ & $\square$ & $\square$ & $\square$ & $\square$ & $\square$ & $\square$ & $0 / 3$ & $14 \leq$ \\
\hline HK483 PB1/MON3 & $\square$ & $\square$ & $\square$ & $\square$ & $\square$ & $\square$ & $\square$ & $\square$ & $2 / 3$ & $6.0(5,7)$ \\
\hline K483 PA/MON3 & $\square$ & $\square$ & $\square$ & $\square$ & $\square$ & $\square$ & $\square$ & $\square$ & $2 / 3$ & $8.0(6,10)$ \\
\hline \483 HA/MON3 & $\square$ & $\square$ & $\square$ & $\square$ & $\square$ & $\square$ & $\square$ & $\square$ & 2/3 & $6.5(6,7)$ \\
\hline HK483 NP/MON3 & $\square$ & $\square$ & $\square$ & $\square$ & $\square$ & $\square$ & $\square$ & $\square$ & $0 / 3$ & $14 \leq$ \\
\hline HK483 NA/MON3 & $\square$ & $\square$ & $\square$ & $\square$ & $\square$ & $\square$ & $\square$ & $\square$ & $3 / 3$ & $5.7(5-7)$ \\
\hline ION3 & $\square$ & $\square$ & $\square$ & $\square$ & $\square$ & $\square$ & $\square$ & $\square$ & $3 / 3$ & $5.7(5-6)$ \\
\hline HK483 NS/MON3 & $\square$ & $\square$ & $\square$ & $\square$ & $\square$ & $\square$ & $\square$ & $\square$ & $0 / 3$ & $14 \leq$ \\
\hline N33 PB2/HK483 & $\square$ & $\square$ & $\square$ & $\square$ & $\square$ & $\square$ & $\square$ & $\square$ & $0 / 3$ & $14 \leq$ \\
\hline ON3 PB1/HK483 & $\square$ & $\square$ & $\square$ & $\square$ & $\square$ & $\square$ & $\square$ & $\square$ & $0 / 3$ & $14 \leq$ \\
\hline MON3 PA/HK483 & $\square$ & $\square$ & $\square$ & $\square$ & $\square$ & $\square$ & $\square$ & $\square$ & $0 / 3$ & $14 \leq$ \\
\hline MON3 HA/HK483 & $\square$ & $\square$ & $\square$ & $\square$ & $\square$ & $\square$ & $\square$ & $\square$ & $0 / 3$ & $14 \leq$ \\
\hline MON3 NP/HK483 & $\square$ & $\square$ & $\square$ & $\square$ & $\square$ & $\square$ & $\square$ & $\square$ & $0 / 3$ & $14 \leq$ \\
\hline /HK483 & $\square$ & $\square$ & $\square$ & $\square$ & $\square$ & $\square$ & $\square$ & $\square$ & $0 / 3$ & $14 \leq$ \\
\hline MON3 M/HK483 & $\square$ & $\square$ & $\square$ & $\square$ & $\square$ & $\square$ & $\square$ & $\square$ & $0 / 3$ & $14 \leq$ \\
\hline MON3 NS/HK483 & $\square$ & $\square$ & $\square$ & $\square$ & $\square$ & $\square$ & $\square$ & $\square$ & $0 / 3$ & $14 \leq$ \\
\hline
\end{tabular}

Figure 1 Pathogenicity of HK483, MON3, and single-gene reassortants in 2-week-old ducks. HK483, MON3, and a series of reassortants between HK483 and MON3 were generated by reverse genetics. Each of the viruses was inoculated into 2-week-old ducks and clinical symptoms of challenged ducks were observed over 14 dpi. White and gray boxes indicate the derivation of virus gene segments from HK483 and MON3, respectively. *: number of dead birds/number of examined ducks. **: mean death dpi. 


\begin{tabular}{|c|c|c|c|c|c|c|c|c|}
\hline \multirow{2}{*}{ Virus } & \multicolumn{6}{|c|}{ Origin of gene segment } & \multirow{2}{*}{ Mortality ${ }^{*}$} & \multirow{2}{*}{$\begin{array}{l}\mathrm{MDD}^{* *} \\
\text { (range) }\end{array}$} \\
\hline & PB2 PB1 PA & $\mathrm{HA}$ & NP & NA & M & NS & & \\
\hline MON3 PB2-NP-NS/HK 483 & $\square \square \square$ & $\square$ & $\square$ & $\square$ & $\square$ & $\square$ & $0 / 5$ & $14 \leq$ \\
\hline $\begin{array}{r}\text { MON3 PB2-PB1-NP } \\
-N S / H K 483\end{array}$ & $\square \square \square$ & $\square$ & $\square$ & $\square$ & $\square$ & $\square$ & $0 / 3$ & $14 \leq$ \\
\hline $\begin{array}{l}\text { MON3 PB2-PA-NP } \\
- \text { NS/HK483 }\end{array}$ & $\square \square \square$ & $\square$ & $\square$ & $\square$ & $\square$ & $\square$ & $0 / 3$ & $14 \leq$ \\
\hline $\begin{array}{l}\text { MON3 PB2-HA-NP } \\
-N S / H K 483\end{array}$ & $\square \square \square$ & $\square$ & $\square$ & $\square$ & $\square$ & $\square$ & $1 / 3$ & 6.0 \\
\hline $\begin{array}{r}\text { MON3 PB2-PB1-PA } \\
\text {-NP-NS/HK483 }\end{array}$ & $\square \square \square$ & $\square$ & $\square$ & $\square$ & $\square$ & $\square$ & $1 / 3$ & 8.0 \\
\hline $\begin{array}{l}\text { MON3 PB2-PB1-HA } \\
\text {-NP-NS/HK483 }\end{array}$ & $\square \square \square$ & $\square$ & $\square$ & $\square$ & $\square$ & $\square$ & $1 / 3$ & 6.0 \\
\hline $\begin{array}{l}\text { MON3 PB2-PA-HA } \\
\text {-NP-NS/HK483 }\end{array}$ & $\square \square \square$ & $\square$ & $\square$ & $\square$ & $\square$ & $\square$ & $3 / 3$ & $5.0(5)$ \\
\hline $\begin{array}{c}\text { MON3 PB2-PB1-PA } \\
\text {-HA-NP-NS/HK483 }\end{array}$ & $\square \square \square$ & $\square$ & $\square$ & $\square$ & $\square$ & $\square$ & $3 / 3$ & $6.7(6-7)$ \\
\hline
\end{tabular}

Figure 2 Pathogenicity of multi-gene reassortants in 2-week-old ducks. A series of multi-gene reassortants between HK483 and MON3 was generated by reverse genetics. Each of the viruses was inoculated into 2-week-old ducks and clinical symptoms of challenged ducks were observed over $14 \mathrm{dpi}$. White and gray boxes indicate the derivation of virus gene segments from HK483 and MON3, respectively. *: number of dead birds/number of examined ducks. ${ }^{* *}$ : mean death dpi.

NP-NS/HK483 died within 5 dpi as did ducks infected with MON3 (Figures 1 and 2). These results indicate that PB2, PA, HA, NP, and NS gene segments of MON3 were the required minimum set to show full pathogenicity in ducks.

\section{Replication of reassortants in 2-week-old ducks}

To further compare viral replication and distribution in ducks of HK483, MON3, and reassortants, virus titers in various tissue samples of ducks infected with these viruses were estimated on $3 \mathrm{dpi}$. Mean titers of MON3 were more than one hundred times as high as those of HK483 in each of the tissues tested (Figure 3). In particular, MON3 was detected at the highest titers in the brains among the tissues examined, while HK483 was not recovered from the brains. Dissemination of singleand multi-gene reassortants in 2-week-old ducks was also assessed on $3 \mathrm{dpi}$ (Figures 4 and 5). Viruses that were lethal to ducks were recovered from various tissues and replicated with high titers especially in the brains. On the other hand, viruses that caused no disease in ducks replicated in restricted organs such as the lungs, kidneys, and colon. These data suggested that acute and efficient viral replication in systemic organs including the brain was the cause of death accompanying neurological symptoms.

\section{Discussion}

Since the outbreaks of HPAI in waterbirds occurred in Hong Kong in 2002, a large number of free-flying water birds have died due to H5N1 HPAIV infection in the last decade; however, little is known about the mechanism whereby these viruses show high pathogenicity in ducks. It has been reported that tyrosine at position 436 of PB1 and threonine at position 516 of PA were associated with high pathogenicity in ducks [23]. Three amino acid residues in PB1-F2 were also reported as determinants of pathogenicity of an H5N1 HPAIV in mallards [24]. Recently, Song et al. [25] demonstrated that proline and aspartic acid at positions 224 and 383, respectively, of

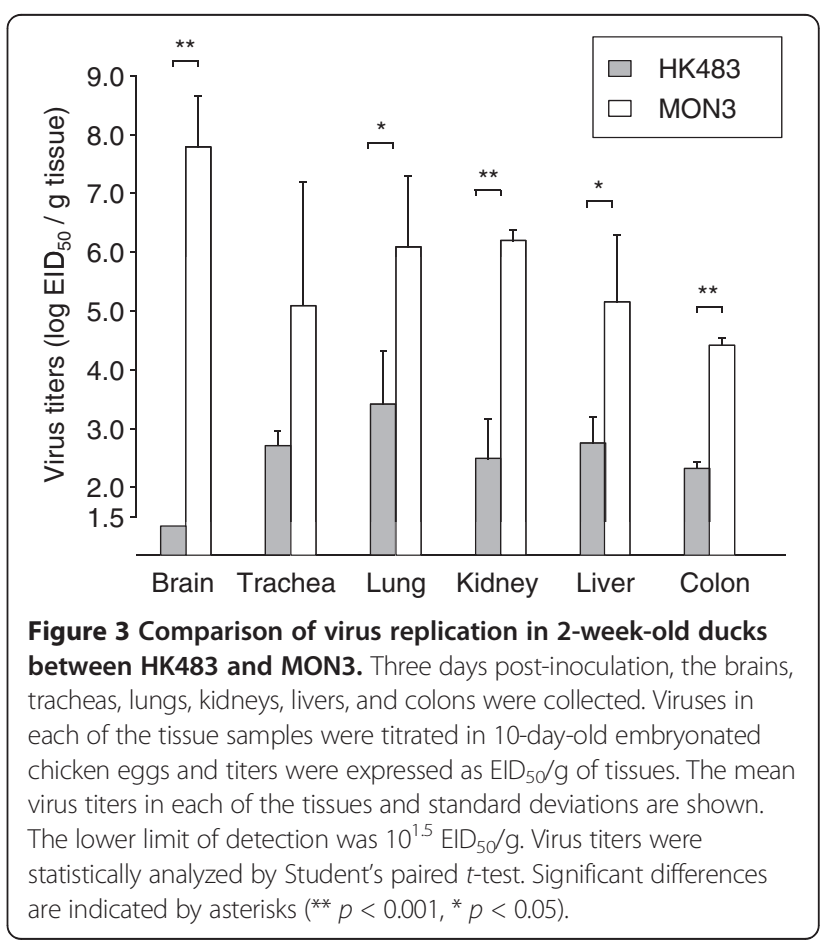




\begin{tabular}{|c|c|c|c|c|c|c|c|c|c|c|c|c|}
\hline \multirow{2}{*}{ Virus } & \multicolumn{6}{|c|}{ Origin of gene segment } & \multicolumn{2}{|c|}{ Virus titer } & \multicolumn{4}{|c|}{ Virus recovery } \\
\hline & PB2 PB1 PA & $\mathrm{HA}$ & $\mathrm{NP}$ & NA & $\mathrm{M}$ & NS & Brain & Lung & Trachea & Kidney & Liver & Colon \\
\hline HK483 PB2/MON3 & $\square \square \square$ & $\square$ & $\square$ & $\square$ & $\square$ ( & $\square$ & $3.8,2.5,2.5$ & $4.8,3.8,4.3$ & ++ & +++ & ++ & ++ \\
\hline HK483 PB1/MON3 & $\square \square \square$ & $\square$ & $\square$ & $\square$ & $\square$ ( & $\square$ & $4.8,3.5,2.8$ & $2.0,5.5,3.5$ & + & +++ & ++ & +++ \\
\hline HK483 PA/MON3 & $\square \square \square$ & $\square$ & $\square$ & $\square$ & $\square$ & $\square$ & $5.3,5.3,-$ & $7.3,2.8,3.5$ & +++ & +++ & +++ & +++ \\
\hline HK483 HA/MON3 & $\square \square \square$ & $\square$ & $\square$ & $\square$ & $\square$ & $\square$ & $6.3,5.3,1.8$ & $6.8,5.3,5.8$ & +++ & +++ & +++ & +++ \\
\hline HK483 NP/MON3 & $\square \square \square$ & $\square$ & $\square$ & $\square$ & $\square$ & $\square$ & $4.8,2.5, \leq 1.8$ & $5.5,4.8,3.3$ & +++ & +++ & ++ & ++ \\
\hline HK483 NA/MON3 & $\square \square \square$ & $\square$ & $\square$ & $\square$ & $\square$ & $\square$ & $7.5,6.5,3.5$ & $3.8,6.3,3.5$ & +++ & +++ & +++ & +++ \\
\hline HK483 M/MON3 & $\square \square \square$ & $\square$ & $\square$ & $\square$ & $\square$ & $\square$ & $9.3,7.8,5.8$ & $5.3,6.3,6.3$ & +++ & +++ & +++ & +++ \\
\hline HK483 NS/MON3 & $\square \square \square$ & $\square$ & $\square$ & $\square$ & $\square$ & $\square$ & $4.3,-,-$ & $5.3,3.5,2.5$ & + & +++ & + & ++ \\
\hline MON3 PB2/HK483 & $\square \square \square$ & $\square$ & $\square$ & $\square$ & $\square$ & $\square$ &,,--- & $2.4,2.0,2.0$ & - & + & - & - \\
\hline MON3 PB1/HK483 & $\square \square \square$ & $\square$ & $\square$ & $\square$ & $\square$ & $\square$ &,,--- &,,--- & - & - & - & + \\
\hline MON3 PA/HK483 & $\square \square \square$ & $\square$ & $\square$ & $\square$ & $\square$ & $\square$ &,,--- & $3.5,3.3,2.0$ & + & + & + & +++ \\
\hline MON3 HA/HK483 & $\square \square \square$ & $\square$ & $\square$ & $\square$ & $\square$ & $\square$ &,,--- & $3.0,2.4,-$ & + & ++ & + & + \\
\hline MON3 NP/HK483 & $\square \square \square$ & $\square$ & $\square$ & $\square$ & $\square$ & $\square$ &,,--- & $4.0,3.5,3.5$ & ++ & +++ & + & + \\
\hline MON3 NA/HK483 & $\square \square \square$ & $\square$ & $\square$ & $\square$ & $\square$ & $\square$ &,,--- & $5.7,4.3,-$ & + & + & - & ++ \\
\hline MON3 M/HK483 & $\square \square \square$ & $\square$ & $\square$ & $\square$ & $\square$ & $\square$ &,,--- & $2.5,2.0,-$ & + & + & + & + \\
\hline MON3 NS/HK483 & $\square \square \square$ & $\square$ & $\square$ & $\square$ & $\square !$ & $\square$ &,,--- & 3.8, 3.5, - & - & - & + & - \\
\hline
\end{tabular}

Figure 4 Replication of single-gene reassortants in 2-week-old ducks. A series of single-gene reassortants between HK483 and MON3 was generated by reverse genetics. Each of the viruses was inoculated into 2-week-old ducks and tissue samples were collected on 3 dpi. Suspension of each tissue sample was inoculated into 10-day-old embryonated eggs for virus titration or recovery. White and gray boxes indicate the derivation of virus gene segments from HK483 and MON3, respectively. Virus titers in tissues were expressed as log EID ${ }_{50} / g$ and the lower limit of detection was $10^{1.5} \mathrm{EID}_{50} / \mathrm{g} .+,++$, and +++ : viruses were recovered from one, two, and three of three birds tested, respectively. -: viruses were not detected from tissue samples.

PA were involved in the virulence of H5N1 HPAIVs in domestic ducks. Here, we showed that the PB2, PA, HA, NP, and NS genes of MON3 were required to show full pathogenicity in ducks. The two strains utilized in the present study, HK483 and MON3, have comparably distant evolutionary relationship amongst H5N1 HPAIVs
[17]. HA genes of HK483 and MON3 were classified into clade 0 and 2.2, respectively [17], and each gene segment of them possesses only $86.3-95.1 \%$ homology (Table 2). However, MON3 and HK483 share the same amino acid residues at all positions reported to be involved in the pathogenicity of H5N1 HPAIVs in ducks,

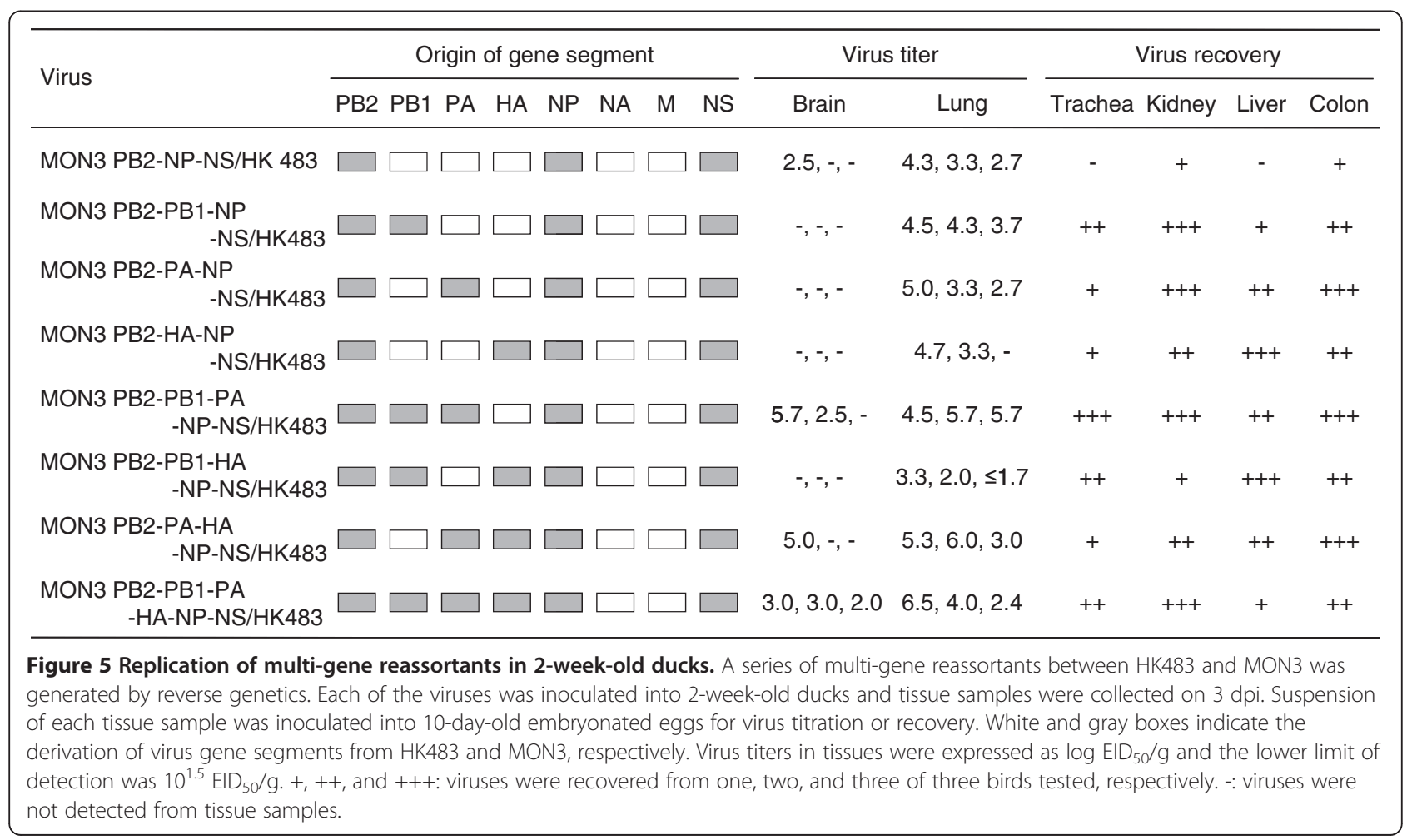




\begin{tabular}{lccc}
$\begin{array}{l}\text { Table } 2 \text { Homology of viral genes and proteins between } \\
\text { HK483 } \text { and MON3 } \\
\text { acleotide } \\
\text { (\%) }\end{array}$ & $\begin{array}{c}\text { Amino acid } \\
(\%)\end{array}$ & $\begin{array}{c}\text { No. of different amino } \\
\text { acids }\end{array}$ \\
\hline PB2 & 86.3 & 96.4 & 27 \\
PB1 & 90.9 & & \\
PB1 & & 97.2 & 21 \\
PB1-F2 & & 80.0 & 18 \\
PA & 88.5 & 95.3 & 34 \\
HA & 95.1 & 94.9 & 39 \\
NP & 92.1 & 97.6 & 12 \\
NA & 88.0 & 90.4 & 43 \\
M & 92.5 & & 12 \\
M1 & & 95.2 & 4 \\
M2 & & 95.9 & 34 \\
NS & 89.8 & & 12 \\
NS1 & & 85.2 & \\
NS2 & & 90.1 & \\
\hline
\end{tabular}

suggesting other molecular determinants for the high pathogenicity of MON3 in ducks.

The present study demonstrated that the PB2, NP, and NS genes of MON3 were prerequisite for high pathogenicity in ducks (Figures 1, 2, 4, and 5). Some explorations to clarify the relationship between the constellation of gene segments and pathogenicity of influenza A viruses were hitherto performed mainly using mammals, such as mice, ferrets, and monkeys [26-29]. These reports showed that the growth potential of reassortants differed depending on the constellation of the polymerase genes, suggesting the major contribution of the polymerases to efficient replication in mammals. NP was also shown to play an important role in the efficient replication and expansion of tissue tropism of H5N1 HPAIVs in chickens [30,31]. Recently, it was demonstrated that the interaction of PB2 and NP with importin- $\alpha$, a host factor mediating trafficking into the nucleus, where transcription and replication of the viral genome occur, was correlated with host adaptation of influenza A viruses [32]. Amino acid differences of the PB2 and NP between HK483 and MON3 are 27 and 12 positions, respectively (Table 2). These differences are probably responsible for the incompatibility of the PB2 and NP of HK483 with viral proteins of MON3 to show high pathogenicity in ducks. Taken together, it is likely that the polymerase and the NP of MON3 may play a principal role in efficient replication in systemic organs of ducks coordinately with employing host factors involved in virus replication.

Sarmento et al. [33] investigated the contribution of the NS gene to the pathogenicity of H5N1 HPAIVs in ducks and discussed that the NS gene products had a minimal influence on the viral pathogenicity in ducks.
Conversely, the present data showed that the NS gene segment of MON3 was also prerequisite for high pathogenicity in ducks (Figures 1 and 4). NS1, encoded in the NS gene, is well known to serve multiple functions in the life cycle of influenza A viruses [34]. The major role of NS1 is considered to be the inhibition of host innate immune responses by limiting interferon production and the subsequent antiviral effects of interferon-induced proteins [34]; therefore, NS1 has been extensively studied as a molecular determinant of viral pathogenicity mainly in mice and chickens. It was recently reported that deletion of amino acid residues 80-84 in NS1, which is a very common characteristic among H5N1 HPAIVs isolated after 2000, enhanced the pathogenicity of $\mathrm{H} 5 \mathrm{~N} 1$ viruses in mice and chickens [35]. It is noteworthy that MON3 also has the deletion of amino acid residues $80-84$ in NS1 but HK483 does not; however, a plausible explanation of how NS1 with the deletion contributes to high pathogenicity is lacking and it is also unclear whether this finding is applicable to the pathogenicity of $\mathrm{H} 5 \mathrm{~N} 1$ viruses in ducks. Recently, Barber et al. [36] demonstrated that the cytoplasmic pathogen sensor RIG-I, triggering antiviral effects by recognition of viral RNA, might be associated with the natural resistance of ducks to influenza A virus infection, while RIG-I homologue of chickens has not been identified. It is known that the NS1 of some strains interacted with RIG-I and blocked its signaling pathway and subsequent interferon- $\beta$ induction [34]; therefore, it is of interest whether the NS1 of MON3 suppresses innate immune responses of ducks more strongly than that of HK483.

Consistent with the data of Pantin-Jackwood et al. [37], the present study showed that the age of ducks is one of the factors which influenced their susceptibility to H5N1 HPAIVs. MON3 killed all of the 1-day- and 2-week-old ducks, but two of the three 4-week-old ducks infected with MON3 survived. While none of the ducks infected with HK483 died, this virus was recovered from the brains of 1-day-old ducks but not from the brains of 2- and 4-week-old ducks. As previously described by Kishida et al. [12], virus replication in the brain might be a cause of death upon HPAIV infection. Neurological symptoms, such as torticollis, blindness, and convulsion, were distinct characteristics of MON3 infection of ducks. MON3 showed considerably strong tropism for the central nervous system of 2-week-old ducks but HK483 were not detected in their brains (Figure 3), suggesting that efficient virus replication in the brain might correlate with neurological dysfunction and death. It is also known that chickens and humans die of multiple organ failure upon H5N1 virus infection [38,39]. In 2-week-old ducks, titers of MON3 were significantly higher than those of HK483 in all of the tissue tested (Figure 3). Furthermore, reassortants lethal to ducks showed wide tissue tropism and 
efficient replication in the lungs and brains (Figures 4 and 5); therefore, multiple organ failure also appeared to be critical for the high pathogenicity of MON3 in ducks.

The present study demonstrated that polygenic factors are involved in the high pathogenicity of MON3. In particular, the PB2, NP, and NS genes of MON3 were prerequisite. Emergence of H5N1 HPAIVs, which caused the death of the water birds in 2002, changed the idea that natural reservoir hosts (i.e., ducks) generally do not die due to influenza A virus infection. H5N1 HPAIVs that emerged in 1997 are still expanding their geographical distribution and the epidemiological study of HPAI in the 2010 migration season suggested the strong possibility that H5N1 HPAIVs might be perpetuated in a migratory bird population in the eastern Eurasian region [40]. These trends underscore the increasing importance of further study on avian influenza in migratory birds. To control HPAI not only in poultry but also in wild birds, the molecular basis of the high pathogenicity of $\mathrm{H} 5 \mathrm{~N} 1$ viruses in ducks should be clarified, in addition to continued global monitoring of HPAIVs in a migratory bird population.

\section{Conclusions}

Experimental infection studies in ducks revealed that the PB2, NP, and NS gene segments of MON3 were prerequisite for the high pathogenicity of MON3 in ducks. A set of the PB2, PA, HA, NP, and NS gene segments of MON3 was required to show full pathogenicity in ducks. These data indicate that multigenic factors are responsible for the pathogenicity of MON3 in ducks. MON3 and reassortants that were lethal to ducks efficiently replicated in the tissues tested, especially in the brain, suggesting a possible correlation between virus growth in the brain and the death of ducks accompanying neurological dysfunction.

\section{Methods}

\section{Viruses and cells}

HK483 was isolated from throat aspirates of the third case of a 13-year-old girl. MON3 was isolated from the brain of a dead whooper swan found at Lake Khunt, Mongolia [17]. Viruses were propagated in 10-day-old embryonated chicken eggs for 48 hours at $35^{\circ} \mathrm{C}$. MadinDarby canine kidney (MDCK) cells and human embryonic kidney $293 \mathrm{~T}$ (293 T) cells were cultured according to Tsuda et al. [41].

\section{Generation of reassortants by reverse genetics}

Viral RNAs of HK483 and MON3 were extracted as described previously [41]. Full-length genomes of the eight gene segments were cloned into a dual-promoter plasmid, pHW2000 [42]. HK483, MON3, and 24 reassortants between HK483 and MON3 were generated by reverse genetics (Figures 1 and 2). Briefly, MDCK and 293 T cells were cocultured in Opti-MEM 1 (Invitrogen) and transfected with $1 \mu \mathrm{g}$ of each of the eight plasmids using TransIT-293 (Mirus Bio) according to the manufacturer's protocol. After six hours of incubation at $37^{\circ} \mathrm{C}$, transfection mixture was replaced with Opti-MEM 1. At 72 hours post-transfection, culture supernatant was collected and injected into the allantoic cavity of 10-day-old chicken embryonated eggs. Virus titers in harvested allantoic fluids were determined by the method of Reed and Muench [43] using embryonated eggs and expressed as $\mathrm{EID}_{50}$ per milliliter.

\section{Experimental infection of ducks}

One-day-, 2-week-, and 4-week-old domestic ducks (Cherry Valley strain) were used to assess the pathogenicity of viruses. Viruses $\left(10^{6.0} \mathrm{EID}_{50}\right.$ in $100 \mu \mathrm{l}$ of allantoic fluid) were inoculated intranasally into three to nine ducks and clinical signs were monitored at 24-hour intervals over $14 \mathrm{dpi}$. Undiluted virus stocks of the following seven reassortants were inoculated into ducks, because their titers in $100 \mu \mathrm{l}$ allantoic fluids did not reach $10^{6.0}$ EID $_{50}$ despite attempts to increase their titers through several passages in embryonated eggs (i.e., $10^{4.7}$, $10^{5.5}, 10^{5.4}, 10^{4.5}, 10^{4.8}, 10^{5.0}$, and $10^{4.5}$ EID $_{50}$ were used for MON3 HA/HK483, MON3 NS/HK483, MON3 PB2PA-NP-NS/HK483, MON3 PB2-HA-NP-NS/HK483, MON3 PB2-PB1-HA-NP-NS/HK483, MON3 PB2-PA-HA-NP-NS/ HK483, and MON3 PB2-PB1-PA-HA-NP-NS/HK483, respectively). Ducks exhibiting severe disease signs were euthanized by intravenous injection of pentobarbital (Dainippon Sumitomo Pharma) and recorded as having died the next day. To examine virus replication, each of the reassortants was inoculated into two or three ducks as described above. On 3 dpi, ducks were euthanized and the brains and lungs of 1-day-old ducks and the brains, tracheas, lungs, kidneys, livers, and colons of 2- and 4-week-old ducks were collected aseptically. To make $10 \%$ suspensions in minimum essential medium (Nissui Pharmaceutical), the tissue samples were homogenized by a Multi-Beads Shocker (Yasui Kikai). Virus titers in these suspensions were determined by the same method as described above and expressed as EID $_{50}$ per gram of tissue.

Experimental infection of ducks was carried out in the biosafety level 3 facilities at the Graduate School of Veterinary Medicine, Hokkaido University, Japan according to the Guidelines for Proper Conduct of Animal Experiments of the Science Council of Japan (http://www.scj.go. jp/ja/info/kohyo/pdf/kohyo-20-k16-2e.pdf). The protocol was approved by the Hokkaido University Animal Care and Use Committee (Permit Number: 08-0157). 


\section{Competing interests}

The authors declare that they have no competing interests.

\section{Authors' contributions}

MK drafted the manuscript. MK, KS, and KM carried out generation of reassortants by reverse genetics and experimental infection of ducks. YS, MO, AT, and HK participated in the coordination of the study. All authors read and approved the final manuscript.

\section{Acknowledgements}

This study was supported by Strategic Funds for the Promotion of Science and Technology (2011-2013), Japan. The present work was supported in part by the Japan Initiative for the Global Research Network on Infectious Diseases (J-GRID), the Program of Founding Research Centers for Emerging and Reemerging Infectious Disease from the Ministry of Education, Culture, Sports, Science, and Technology, Japan, and Japan Racing and Livestock Promotion Foundation. Gratitude is expressed to Dr. M. Tashiro, National Institute of Infectious Diseases, Tokyo, Japan, for his generous donation of A/ Hong Kong/483/1997 (H5N1). We also wish to thank Takikawa Shinseien, Hokkaido, Japan for providing the domestic ducks in this study. In addition, we would like to thank $\mathrm{H}$. Shibuya for sequencing.

\section{Author details}

'Department of Disease Control, Graduate School of Veterinary Medicine, Hokkaido University, Sapporo, Hokkaido 060-0818, Japan. ${ }^{2}$ Research Center for Zoonosis Control, Hokkaido University, Sapporo, Hokkaido 001-0020, Japan. ${ }^{3}$ Present address: Division of Global Epidemiology, Research Center for Zoonosis Control, Hokkaido University, Sapporo, Hokkaido 001-0020, Japan. ${ }^{4}$ Present address: Avian Zoonosis Research Center, Faculty of Agriculture, Tottori University, Tottori 680-8553, Japan.

Received: 11 July 2012 Accepted: 28 January 2013 Published: 2 February 2013

\section{References}

1. Kawaoka Y, Cox NJ, Haller O, Hongo S, Kaverin N, Klenk HD, Lamb RA, McCauley J, Palese P, Rimstad E, Webster RG: Family Orthomyxoviridae. In Virus Taxonomy. 8th edition. Edited by Fauquet CM, Mayo MA, Maniloff J, Desselberger U, Ball LA. California: Elsevier Academic Press; 2005:681-693.

2. Fouchier RA, Munster V, Wallensten A, Bestebroer TM, Herfst S, Smith D, Rimmelzwaan GF, Olsen B, Osterhaus AD: Characterization of a novel influenza A virus hemagglutinin subtype (H16) obtained from blackheaded gulls. J Virol 2005, 79:2814-2822.

3. Ito T, Okazaki K, Kawaoka Y, Takada A, Webster RG, Kida H: Perpetuation of influenza A viruses in Alaskan waterfowl reservoirs. Arch Virol 1995, 140:1163-1172.

4. Okazaki K, Takada A, Ito T, Imai M, Takakuwa H, Hatta M, Ozaki H, Tanizaki T, Nagano T, Ninomiya A, Demenov VA, Tyaptirganov MM, Karatayeva TD, Yamnikova SS, Lvov DK, Kida H: Precursor genes of future pandemic influenza viruses are perpetuated in ducks nesting in Siberia. Arch Virol 2000, 145:885-893.

5. Kida H, Yanagawa R, Matsuoka Y: Duck influenza lacking evidence of disease signs and immune response. Infect Immun 1980, 30:547-553.

6. Kida H, Kawaoka Y, Neave CW, Webster RG: Antigenic and genetic conservation of H3 influenza virus in wild ducks. Virology 1987, 159:109-119.

7. Kida H: Ecology of influenza viruses in nature, birds, and humans. Glob Environ Res 2008, 12:9-14.

8. Alexander DJ: A review of avian influenza in different bird species. Vet Microbiol 2000, 74:3-13.

9. Shortridge KF, Zhou NN, Guan Y, Gao P, Ito T, Kawaoka Y, Kodihalli S, Krauss S, Markwell D, Murti KG, Norwood M, Senne D, Sims L, Takada A, Webster RG: Characterization of avian H5N1 influenza viruses from poultry in Hong Kong. Virology 1998, 252:331-342.

10. Centers for Disease Conrrol and Prevention (CDC): Isolation of avian influenza $\mathrm{A}(\mathrm{H} 5 \mathrm{~N} 1)$ viruses from humans--Hong Kong, May-December 1997. MMWR Morb Mortal Wkly Rep 1997, 46:1204-1207.

11. Webster RG, Govorkova EA: H5N1 influenza-continuing evolution and spread. N Engl J Med 2006, 355:2174-2177.
12. Kishida N, Sakoda Y, Isoda N, Matsuda K, Eto M, Sunaga Y, Umemura T, Kida H: Pathogenicity of H5 influenza viruses for ducks. Arch Virol 2005, 150:1383-1392.

13. Sturm-Ramirez KM, Ellis T, Bousfield B, Bissett L, Dyrting K, Rehg JE, Poon L, Guan Y, Peiris M, Webster RG: Reemerging H5N1 influenza viruses in Hong Kong in 2002 are highly pathogenic to ducks. J Virol 2004, 78:4892-4901.

14. Chen H, Smith GJ, Zhang SY, Qin K, Wang J, Li KS, Webster RG, Peiris JS, Guan Y: Avian flu: H5N1 virus outbreak in migratory waterfowl. Nature 2005, 436:191-192

15. Liu J, Xiao H, Lei F, Zhu Q, Qin K, Zhang XW, Zhang XL, Zhao D, Wang G, Feng Y, Ma J, Liu W, Wang J, Gao GF: Highly pathogenic H5N1 influenza virus infection in migratory birds. Science 2005, 309:1206.

16. Wang G, Zhan D, Li L, Lei F, Liu B, Liu D, Xiao H, Feng Y, Li J, Yang B, Yin Z, Song X, Zhu X, Cong Y, Pu J, Wang J, Liu J, Gao GF, Zhu Q: H5N1 avian influenza re-emergence of Lake Qinghai: phylogenetic and antigenic analyses of the newly isolated viruses and roles of migratory birds in virus circulation. J Gen Virol 2008, 89:697-702.

17. Sakoda Y, Sugar S, Batchluun D, Erdene-Ochir TO, Okamatsu M, Isoda N, Soda K, Takakuwa H, Tsuda Y, Yamamoto N, Kishida N, Matsuno K, Nakayama E, Kajihara M, Yokoyama A, Takada A, Sodnomdarjaa R, Kida H: Characterization of $\mathrm{H} 5 \mathrm{~N} 1$ highly pathogenic avian influenza virus strains isolated from migratory waterfowl in Mongolia on the way back from the southern Asia to their northern territory. Virology 2010, 406:88-94.

18. Okamatsu M, Tanaka T, Yamamoto N, Sakoda Y, Sasaki T, Tsuda Y, Isoda N, Kokumai N, Takada A, Umemura T, Kida H: Antigenic, genetic, and pathogenic characterization of H5N1 highly pathogenic avian influenza viruses isolated from dead whooper swans (Cygnus cygnus) found in northern Japan in 2008. Virus Genes 2010, 41:351-357.

19. Uchida Y, Mase M, Yoneda K, Kimura A, Obara T, Kumagai S, Saito T, Yamamoto Y, Nakamura K, Tsukamoto K, Yamaguchi S: Highly pathogenic avian influenza virus (H5N1) isolated from whooper swans. Japan. Emerg Infect Dis 2008, 14:1427-1429.

20. Senne DA, Panigrahy B, Kawaoka Y, Pearson JE, Suss J, Lipkind M, Kida H, Webster RG: Survey of the hemagglutinin (HA) cleavage site sequence of $\mathrm{H} 5$ and $\mathrm{H} 7$ avian influenza viruses: amino acid sequence at the $\mathrm{HA}$ cleavage site as a marker of pathogenicity potential. Avian Dis 1996, 40:425-437.

21. Park $\mathrm{CH}$, Ozaki H, Takada A, Kida H, Ochiai K, Umemura T: Primary target cells of virulent strains of type A influenza virus in chicken embryos. Avian Pathol 2001, 30:269-272.

22. Muramoto Y, Ozaki H, Takada A, Park CH, Sunden Y, Umemura T, Kawaoka $\mathrm{Y}$, Matsuda $\mathrm{H}$, Kida $\mathrm{H}$ : Highly pathogenic $\mathrm{H} 5 \mathrm{~N} 1$ influenza virus causes coagulopathy in chickens. Microbiol Immunol 2006, 50:73-81.

23. Hulse-Post DJ, Franks J, Boyd K, Salomon R, Hoffmann E, Yen HL, Webby RJ, Walker D, Nguyen TD, Webster RG: Molecular changes in the polymerase genes (PA and PB1) associated with high pathogenicity of H5N1 influenza virus in mallard ducks. J Virol 2007, 81:8515-8524.

24. Marjuki H, Scholtissek C, Franks J, Negovetich NJ, Aldridge JR, Salomon R, Finkelstein D, Webster RG: Three amino acid changes in PB1-F2 of highly pathogenic $\mathrm{H} 5 \mathrm{~N} 1$ avian influenza virus affect pathogenicity in mallard ducks. Arch Virol 2010, 155:925-934.

25. Song J, Feng H, Xu J, Zhao D, Shi J, Li Y, Deng G, Jiang Y, Li X, Zhu P, Guan $Y, B u Z$, Kawaoka $Y$, Chen H: The PA protein directly contributes to the virulence of H5N1 avian influenza viruses in domestic ducks. J Virol 2011, 85:2180-2188.

26. Snyder MH, Buckler-White AJ, London WT, Tierney EL, Murphy BR: The avian influenza virus nucleoprotein gene and a specific constellation of avian and human virus polymerase genes each specify attenuation of avianhuman influenza A/Pintail/79 reassortant viruses for monkeys. J Virol 1987, 61:2857-2863.

27. Salomon R, Franks J, Govorkova EA, Ilyushina NA, Yen HL, Hulse-Post DJ, Humberd J, Trichet M, Rehg JE, Webby RJ, Webster RG, Hoffmann E: The polymerase complex genes contribute to the high virulence of the human H5N1 influenza virus isolate A/Vietnam/1203/04. J Exp Med 2006, 203:689-697.

28. Rudneva IA, Timofeeva TA, Shilov AA, Kochergin-Nikitsky KS, Varich NL, Ilyushina NA, Gambaryan AS, Krylov PS, Kaverin NV: Effect of gene constellation and postreassortment amino acid change on the phenotypic features of H5 influenza virus reassortants. Arch Virol 2007, 152:1139-1145. 
29. Maines TR, Chen LM, Belser JA, Van Hoeven N, Smith E, Donis RO, Tumpey $T M$, Katz JM: Multiple genes contribute to the virulent phenotype observed in ferrets of an H5N1 influenza virus isolated from Thailand in 2004. Virology 2011, 413:226-230.

30. Wasilenko JL, Lee CW, Sarmento L, Spackman E, Kapczynski DR, Suarez DL, Pantin-Jackwood MJ: NP, PB1, and PB2 viral genes contribute to altered replication of H5N1 avian influenza viruses in chickens. J Virol 2008, 82:4544-4553.

31. Tada T, Suzuki K, Sakurai Y, Kubo M, Okada H, Itoh T, Tsukamoto K: NP body domain and PB2 contribute to increased virulence of H5N1 highly pathogenic avian influenza viruses in chickens. J Virol 2011, 85:1834-1846,

32. Gabriel G, Klingel K, Otte A, Thiele S, Hudjetz B, Arman-Kalcek G, Sauter M, Shmidt T, Rother F, Baumgarte S, Keiner B, Hartmann E, Bader M, Brownlee GG, Fodor E, Klenk HD: Differential use of importin-a isoforms governs cell tropism and host adaptation of influenza virus. Nat Commun 2011, 2:156

33. Sarmento L, Wasilenko J, Pantin-Jackwood M: The effects of NS gene exchange on the pathogenicity of H5N1 HPAl viruses in ducks. Avian Dis 2010, 54(Suppl 1):532-537.

34. Hale BG, Randall RE, Ortín J, Jackson D: The multifunctional NS1 protein of influenza A viruses. J Gen Virol 2008, 89:2359-2376.

35. Long JX, Peng DX, Liu YL, Wu YT, Liu XF: Virulence of H5N1 avian influenza virus enhanced by a 15 -nucleotide deletion in the viral nonstructural gene. Virus Genes 2008, 36:471-478.

36. Barber MR, Aldridge JR Jr, Webster RG, Magor KE: Association of RIG-I with innate immunity of ducks to influenza. Proc Natl Acad Sci USA 2010, 107:5913-5918.

37. Pantin-Jackwood MJ, Suarez DL, Spackman E, Swayne DE: Age at infection affects the pathogenicity of Asian highly pathogenic avian influenza H5N1 viruses in ducks. Virus Res 2007, 130:151-161.

38. Yuen KY, Chan PK, Peiris M, Tsang DN, Que TL, Shortridge KF, Cheung PT, To WK, Ho ET, sung R, Cheng AF: Clinical features and rapid viral diagnosis of human disease associated with avian influenza A H5N1 virus. Lancet 1998, 351:467-471.

39. To KF, Chan PK, Chan KF, Lee WK, Lam WY, Wong KF, Tang NL, Tsang DN, Sung RY, Buckley TA, Tam JS, Cheng AF: Pathology of fatal human infection associated with avian influenza A H5N1 virus. J Med Virol 2001, 63:242-246

40. Kajihara M, Matsuno K, Simulundu E, Muramatsu M, Noyori O, Manzoor R, Nakayama E, Igarashi M, Tomabechi D, Yoshida R, Okamatsu M, Sakoda Y, Ito K, Kida H, Takada A: An H5N1 highly pathogenic avian influenza virus that invaded Japan through waterfowl migration. Jpn J Vet Res 2011, 59:89-100.

41. Tsuda Y, Isoda N, Sakoda Y, Kida H: Factors responsible for plaque formation of A/duck/Siberia/272/1998 (H13N6) influenza virus on MDCK cells. Virus Res 2009, 140:194-198.

42. Hoffmann E, Neumann G, Kawaoka Y, Hobom G, Webster RG: A DNA transfection system for generation of influenza $A$ virus from eight plasmids. Proc Natl Acad Sci USA 2000, 97:6108-6113.

43. Reed $\mathrm{L}$, Muench $\mathrm{H}$ : A simple method of estimating 50 per cent end-points. Am J Hyg 1938, 27:493-497.

\section{Submit your next manuscript to BioMed Central and take full advantage of:}

- Convenient online submission

- Thorough peer review

- No space constraints or color figure charges

- Immediate publication on acceptance

- Inclusion in PubMed, CAS, Scopus and Google Scholar

- Research which is freely available for redistribution 